\title{
“Is Quality Ensuring to Get Competitive Advantages in Auto Manufacturing Industries?" -A Study of Volvo Group
}

\author{
Muhammed Zakir Hossain, Mayesha Tasnim, Mohammad Raihanul Hasan \\ Department of Business Studies, State University of Bangladesh, Dhaka, Bangladesh \\ Email: zakir_sub2013@yahoo.com
}

How to cite this paper: Hossain, M.Z., Tasnim, M. and Hasan, M.R. (2017) Is Quality Ensuring to Get Competitive Advantages in Auto Manufacturing Industries?-A Study of Volvo Group. American Journal of Industrial and Business Management, 7, 48-68.

http://dx.doi.org/10.4236/ajibm.2017.71005

Received: November 30, 2016

Accepted: January 19, 2017

Published: January 22, 2017

Copyright $\odot 2017$ by authors and Scientific Research Publishing Inc. This work is licensed under the Creative Commons Attribution International License (CC BY 4.0).

http://creativecommons.org/licenses/by/4.0/

\begin{abstract}
In today's business world “Total Quality Management" strategy is utmost important for a company in order to survive in the rapidly growing competitive market. It helps a company to increase the level of competence and allows it to compete in the market. To meet expected superior need of customers, Volvo delivers cleaner, safer and smarter transport solutions by concentrating on solutions-based approach since its inception. This core value of Volvo is urging to conduct a qualitative study on quality of Volvo toward attaining competitive advantage. This study attempted to investigate the role of quality management on Volvo's competitiveness through a case study method. While exploring the secondary data, this study found that attributes such as dynamic leadership, positive and ethical corporate culture, customer centric orientation, empowering employees helped Volvo to achieve competitive advantage over its competitor. This study also found that practicing Six Sigma, maintaining quality and ISO standards, and establishing quality council have a positive role in attaining Volvo's operational excellences and in achieving well-functioning society. Volvo's strategy of winning competitive advantage is an example which should be followed by others to achieve competitive advantage in order to be able to sustain in today's highly competitive market and keeping pace with rapid changes.
\end{abstract}

\section{Keywords}

Quality, Total Quality Management, Costs of Quality, Competitive Advantages, Volvo

\section{Introduction}

The rapid technological advancement and dynamic customers' obligations brought this world into one common and narrow market. New businesses are opening 
day by day with new products and services. Today, sustainability is the biggest question mark for every business in this fast growing competitive market. Therefore, in order to survive in this competitive economy, every organization has to increase the level of its competence. Competence can be enhanced by implementing quality and total quality management strategy in company's business model. But, quality is a very sensitive phenomenon either the organization is big or small. The success and failure of the organization depend upon the quality management system within the organization. The total quality product or service helps to distinguish the organizations that are able to gain competitive advantage. According to Deming (1982), the main aim of total quality management (TQM) is to build a sustainable competitive advantage by providing customer satisfaction through cost efficient way [1]. In other words, a company that adopts a total quality management always intends to provide best products or services in a fair cost. For this regard, a company always thinks about continuous improvement on a timely basis so that it can achieve sustainable competitive advantage.

In last decades, quality became an interesting and hot spot of discussion especially in the western world. The Japanese industry achieved a lot of success and managed to gain a competitive edge and it's all due to successful focus on quality and quality related issues [2]. The quest for quality improvement has become a highly desired objective in today's intensely competitive global market-place. Quality management has been reckoned as the prime mover for enhanced business performance [3]. This increased interest in the quality and quality improvement opened the doors for a new theoretical thinking to emerge; theories concentrating mainly on quality and the way to manage quality. These ideas and principles resulted is what's called nowadays of Total Quality Management (TQM). The concept of TQM is generally understood, and often also described, as some form of "management philosophy" based on a number of core values, such as customer focus, continuous improvement, process orientation, everybody's commitment, fast response, result orientation and learn from others.

In this paper, one of the leading manufacturing companies "Volvo" has been chosen which is known for its strong "Total Quality Management", unique corporate culture, Employee centring services which helps Volvo to gain competitive advantage over its competitors.

\subsection{Purpose and Research Significances}

This paper aims at studying and analyzing Volvo's strategies and overall techniques of maintain ISO standard quality in order to understand how Volvo has achieved competitive advantage and keeping pace with changes. This paper also will reflect on quality management related topics, specially the aspects of profitability and competitive advantage resulting from Quality management. It will show some of most common definitions of quality used today, and the models used to manage quality and its determined dimensions. In order to gain a better understanding of the quality and quality management models and concepts researchers will try to focus on the managerial strategic point of view rather than 
an operational point of view.

From both academic and practical point of view this research is significant as it has systematically analyses the factors which works for gaining competitive advantage, which can be utilized by other companies to achieve "Total Quality" and also the research paper can be used as lead for others to study further in this issue.

\subsection{Methodology}

This paper is entirely based on secondary information and researchers will try to use an empirical case study approach to describe the quality efforts made and planned by a business organization. In this case, it will be Volvo (a major automobile manufacturer in the automotive industry). The study is based on theories on quality management to gain competitive advantage and TQM. Following the theoretical discussion, the paper presents the empiricism on the company's quality management efforts to get competitive advantage in terms of thinking, strategies and practices. This empirical study is followed by an analysis based upon the theories to have an insight to their quality efforts for competitive advantage and tries to find areas for further improvement.

\section{Literature Review}

To get a profound view on this research topic, numbers of quality full secondary data have been analyzed carefully. The review has been divided into eight sections which deal with (as shown in Table 1): Quality, Total quality Management, Quality to gain competitive advantage, Quality control, Quality function deployment, Cost of quality, ISO 9000 certification and Six Sigma. Briefly the literature review deals with the following:

\subsection{Quality}

The word "quality" is derived from the Latin word "qualities" which means "of what" [2]. Quality can be defined as "the degree to which the product in use will meet the expectations of the customer" [4]. Corsby (1979) defined quality as the "confirmation to requirement" [5]. Bergman \& Klefsjö (2010) define quality as the "ability to satisfy, or preferably exceed, the needs and expectations of the customers". Federal Express describes "Quality is the presence of value defined by customers" [2]. According to Bergman \& Klefsjö these definitions of quality are designed from both production and customer point of view. These views are related to the quality dimensions of goods and service. According to Bergman and Klefsjö quality dimensions of goods include reliability, performance, safety, durability, maintainability, environmental impact, appearance and flawlessness. On the other hand, reliability, credibility, access, communication, responsiveness, courtesy, empathy and tangibles are the main dimensions of services.

Gravin (1984) presented five different approaches to define quality [6]. They are: the transcendent approach, product-based approach, user-based approach, 
Table 1. Summary of Literature Review.

\begin{tabular}{|c|c|c|}
\hline Major Focus & Area & Study \\
\hline Quality & $\begin{array}{l}\text { Meaning, dimension and } \\
\text { approaches of quality. }\end{array}$ & $\begin{array}{l}\text { Bergman \& Klefsjö (2010), Feigenbaum (1961), } \\
\text { Corsby (1979), Gravin (1984) }\end{array}$ \\
\hline $\begin{array}{l}\text { Total quality } \\
\text { management }\end{array}$ & $\begin{array}{l}\text { Concept, principles, } \\
\text { output, and HRM issues } \\
\text { of TQM }\end{array}$ & $\begin{array}{l}\text { Prajogo and McDermott (2005). Rad (2006), Ho } \\
\text { and Fund (1994), Dean and Bowen (1994), } \\
\text { Bergman and Klefsjö (2010), Hoogevorst et al. } \\
\text { (2005) }\end{array}$ \\
\hline $\begin{array}{l}\text { Quality to gain } \\
\text { competitive } \\
\text { advantage: }\end{array}$ & $\begin{array}{l}\text { Competitive dynamics: } \\
\text { Cause and effect }\end{array}$ & $\begin{array}{l}\text { Beal and Lockamy III (1999), Mehra and Agrawal } \\
\text { (2003), Hill (1995), Venkatraman and Prescott, } \\
\text { 1990, Reed et.al (1996), Shenawy } \\
\text { et al. (2007), Deming (1982), Brah et al. (2002), } \\
\text { Joiner (2007), Shenawy et.al (2007), Powell (1995), } \\
\text { Mehera and Agrawal (2003). Helms (1996) }\end{array}$ \\
\hline Quality control & $\begin{array}{l}\text { Steps and process of } \\
\text { quality control }\end{array}$ & $\begin{array}{l}\text { Jabnoum (2002), Juran (1989), Ozeki and Asaka } \\
\text { (1990), Ozeki and Asaka (1990), }\end{array}$ \\
\hline $\begin{array}{l}\text { Quality Function } \\
\text { Deployment (QFD) }\end{array}$ & $\begin{array}{l}\text { Meaning, classification } \\
\text { and impact, of QFD }\end{array}$ & $\begin{array}{l}\text { Yoji Akao (1966), Bergman \& Klefsjö, (2010). } \\
\text { Bergman \& Klefsjö (2010) }\end{array}$ \\
\hline Cost of Quality & $\begin{array}{l}\text { Cost and quality } \\
\text { relationship }\end{array}$ & Laszlo (1997). \\
\hline $\begin{array}{l}\text { ISO } 9000 \\
\text { Certification }\end{array}$ & $\begin{array}{l}\text { Standards and } \\
\text { guidelines of ISO }\end{array}$ & $\begin{array}{l}\text { ISO (2010a), (2010b), Singles et al. (2001), } \\
\text { Johannsen 1996, }\end{array}$ \\
\hline Six Sigma & $\begin{array}{l}\text { Meaning, uses and } \\
\text { importance of six sigma }\end{array}$ & $\begin{array}{l}\text { Watson and de Yong (2010), Green (2006), Kwak } \\
\text { and Anbari (2006), }\end{array}$ \\
\hline
\end{tabular}

manufacturing-based approach and value-based approach. According to transcendent approach quality cannot be defined precisely, we can learn it through experience. The product-based approach describes that quality is precise and measurable. The user-based approach states that different customers have different need and expectation thus the quality can be judged only by the customers. The manufacturing-based approach defines quality as conformance to requirement and focused on the cost reduction. Finally, value-based approach deals quality in terms of cost and price.

\subsection{Total Quality Management}

Total quality management (TQM) can be defined as the model that aims to meet customers' needs and expectations through continuous improvement of the quality of goods and services by integrating all functions and process within the organization [7]. Rad (2006) defined TQM as the development of an organizational culture [8]. The organizational culture in this regard refers with continuous improvement for the total customer satisfaction through integrated systems of techniques and tools [8]. By implementing TQM, an organization can improve its effectiveness, efficiency, flexibility and competitiveness [9] thus will 
achieve competitive advantage. It is because customer focus, continuous improvement and team work are the major principles of TQM [10]. Bergman and Klefsjö (2010: pp. 36-37) defined TQM as "a constant endeavor to fulfill, and preferably exceed, customer needs and expectations at the lowest cost, by continuous improvement work, to which all involved are committed, focusing on the processes in the organization" [2]. With this description, TQM is a continuous process of change and improvement of the products or services to exceed the needs of customers' expectations at a lowest possible cost without compromising the quality. According to Bergman and Klefsjö (2010), TQM is a holistic concept on which values, methodologies and tools are combined in order to achieve higher level of customer satisfaction through optimum utilization of minimum resources [2].

Further, Bergman and Klefsjö (2010) described that a company will be get benefitted only, if the quality strategy is developed on the top management's continuous and consistent dedication to quality issues [2]. Therefore, the improvement work should be on the basis of company's six values, which according to Bergman and Klefsjö (2010) are the cornerstones of TQM. The company's values include: committed leadership, focus on customers, base decisions on facts, focus on processes, improve continuously, and let everybody be committed (as shown in Figure 1). Figure 1 provides clear pictures on these cornerstones of TQM.

These six values, the cornerstones of TQM, are interrelated and interconnected with each other [2]. According to the authors, the leadership and management roles bind these values together for the efficient and successful quality improvements.

Hoogevorst et al. (2005) suggests that for the success of total quality management employees' behavior also should be determined [11]. Employees' attention to organizational culture, management practices and organizational structures and system are the comprehensive variables that determine the employees' behavior [11]. These variables according to Hoogevorst et al. (2005) should be aligned in TQM practices.

\section{Cornerstone Model of TQM}

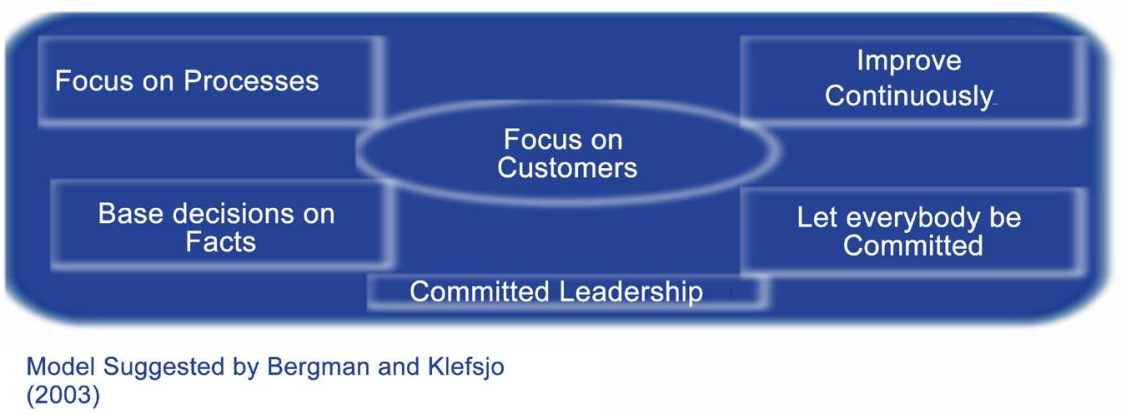

Figure 1. Cornerstone model of TQM suggested by bergman and klefsjo. 


\subsection{Quality to Gain Competitive Advantage}

The nature of industrial competition has been changing due to the fast growing modern competitive globalized economy, rapid technological developments and dynamic customers' obligations [12]. Due to the changing nature of the environment and competitive globalized economy, business cannot depend only upon their domestic practices ([13]. In this competitive economy, monetary is not only the factor that can compete and create sustainable competitive advantage [14]. There must be revised quality-based [13] and strong competitive strategies according to the requirements and expectations from the environmental factors [12]. To gain the competitive advantage and to attain world-class performance levels many companies are focused on the product, process and service quality improvement and integrate it as the key strategic policy [15].

However, according to Beal and Lockamy III (1999), sustainable world-class performance to create competitive advantage will not be possible if the company's competitive strategy and the requirements of environment do not match. Therefore, to gain competitive advantage there must be alignment between the company's competitive strategy and the environmental requirements [16]. The competitive strategy of the firm refers with TQM content and process [17]. Therefore the balance between process and content should be required in order to get competitive advantage [17]. Quality or the cost efficiency may promote a firm toward sustainable competitive advantage through the alignment with environmental factors [17]. Reed et al. (1996) believed that focus on the process provide customer satisfaction and reduced cost, which are the key sources of competitive advantage. Therefore, TQM can be defined as the top management commitment, teams, culture, training, and process efficiency [18]. The combination of these components creates the focus on process [17] and each of these components leads to achieve competitive advantage [17] [18]. Top management or the leaders can have clear indication of the successful component of TQM program [18]. Thus the clear vision should be applied by the managers to achieve competitive advantage [18].

According to Deming (1982) the main aim of total quality management (TQM) is to build a sustainable competitive advantage by providing customer satisfaction through cost efficient way. Brah et al. (2002) describe, the companies that have adopted TQM achieve competitive advantages over the companies that have not [19]. In other word, the company that is committed toward continuous improvement, motivate its' employee for the quality output and exceed the customers' expectations to achieve competitive advantage [20]. Likewise, Shenawy et al. (2007) believes TQM as a business strategy that leads to achieve competitive advantage. In other word, there is a positive relationship between adopting TQM and achieving competitive advantage.

Further, Powell (1995) suggests certain features of TQM such as behavioral, imperfectly imitable features like an open culture, employee empowerment and executive commitment are vital to create competitive advantage [21]. According to Mehera and Agrawal (2003) in order to get competitive advantage cultural, 
social and business environments of a specific global location need to be considered carefully while planning for desired quality objectives.

Furthermore, according to Helms (1996), managers are the persons who can judge about the improvements of new procedures and methods in various ways [22]. Managers can evaluate market shares, which can be increased by using a customer-driven, demand pull strategy [22]. If the designed quality is implemented, the amount of defective products and scrap material will reduce [22]. Further, if the employees are involved in quality and productivity, their satisfaction level will increase and provide more commitment towards their duty [22]. By doing so, a firm will able to increase its productivity level and thereby will gain competitive advantages among the competitors.

\subsection{Quality Control}

To meet the need of customer and for the continuous improvement [23], quality control is an effective tool. Juran (1989) came with three steps of control process. They are: evaluating performance, comparing the actual performance with goal and taking action on the difference [24]. Similarly, Ozeki and Asaka (1990) present PDCA quality control mechanism [25]. The PDCA quality control includes following steps:

- Plan : Determine your goals and develop a process for achieving these goals

- Do: Implement your plan

- Check: Evaluate the results of your plan and its implementation

- Actions: Take the necessary action constituting quality control [25].

Jabnoun (2002) concludes that control process in total quality management also believes to empower the employees to check and improve quality. He further explain that in order to meet customer expectations, it gives pressures to top management to provide necessary input of structure, skills, system and shared values.

\subsection{Quality Function Deployment (QFD)}

Quality is directed toward meeting and exceeding customer expectations. To gain competitive advantage, organizations not only have to provide high quality service but also have to focus on the demand of customers. QFD is a systematic approach for product and service design based on the customer desires [26]. This methodology was developed by Yoji Akao in Japan in 1966 [26]. QFD has focused on the process of communication and participation with the customers, so that customers demand can be identified and implemented to improve the service quality [2].

QFD method helps to determine how and where customer priorities are to be assigned in the different stages of product development process. Bergman \& Klefsjö (2010) describes, QFD method can be further divided into four major parts:

- Market analysis: Existing and potential customer's opinion on services.

- Competitors' analysis: marketing research, strategies to deal with customer 
needs and expectations.

- Identify key factors: competitors key strategies.

- Translating key factors: competitors' weak strategies.

Prioritizing customer desires, converting these needs into product development phase and producing quality product and services to satisfy customer needs are the major objectives shared by QFD [26].

\subsection{Cost of Quality}

The cost of quality approach concern with the balance of cost of assuring quality against the cost associated with problems attributed to a lack of quality [27]. According to Laszlo (1997), an effective quality improvement program can be designed in order to lessen the total cost of quality. To reduce the quality cost, there should be balance among the four elements of quality cost. Those four elements are: prevention, appraisal, internal failures and external failures [27]. He further explains, the prevention and appraisal costs are the investments which are predetermined by plans and budgets in order to improve quality. The prevention and appraisal costs are under the control of management. On the other hand, the costs of internal failure are associated with the errors and problems within the operation. The costs of external failures are the expenses associated with errors and problems with the products and services which are offered to the customers [27]. According to the author, both internal and external failures are due to some circumstances, which are out of control of management.

These costs can be minimized through quality cost control [27]. The quality cost control includes planning investments in quality improvement projects that will result in adequately high levels of cost avoidance to offset the initial investments [27]. As described Laszlo (1997) properly managed quality improvement projects are cost-effective which helps to avoid cost through quality improvement. The quality improvement projects provide higher level of customer satisfaction through waste reductions which are associated with errors [27]. Through the effective quality improvement projects, an organization can enhance its competence level and thus able to gain competitive advantage.

\subsection{ISO 9000 Certification}

ISO 9000 family is an international consensus on good quality management practices, which includes standards and guidelines relating to quality management systems and other supporting standards [28]. In other word, ISO 9000 refers to the quality management on which an organization ties to fulfill: customer's quality requirement; applicable regulatory requirements; enhance customer satisfaction; achieve continual improvement of its performance in pursuit of this objectives [29]. Furthermore, Singles et al. (2001) defines ISO 9000 certification as the minimum requirements of quality that every organization should meet and assure about a consistent quality of product, services and processes [30]. According to Johannsen 1996, ISO 9000 standards provide quality assurance of supplier-customer relationship through third-party certification [31]. However, 
the ISO certification itself neither leads to an improvement for the organizational performance nor it will have better supplier [30]. In other word, motivational factor plays vital role to improve its performance level and to get result in certification [30].

\subsection{Six-Sigma}

Six Sigma is the six-step process introduced by Motorola University Design for manufacturing training and program in 1988 [32]. Since then, it has extended to total quality management [33]. Today Six Sigma is considered as a business strategy that focuses on customer requirements, business productivity and financial performance [34]. According to Ball et al. (2010) Six Sigma can be interpret in four ways: a set of statistical tools, an operational philosophy of management, a business culture and an analysis methodology that uses the scientific methods where the main objectives of Six Sigma are improving quality efficiency, profitability and capability in the process [35].

\section{Empiricism}

\subsection{Background of the Organization}

Volvo was officially founded on April 14, 1927 by Assar Gabrielsson and Gustaf Larson with a mutual agreement on constructing a Swedish car [36]. After that period, Volvo has developed from a small local industry to one of the world's largest manufacturer of heavy trucks, cars, busses and construction equipments [37]. Volvo is providing the product and services, related to the transportation industry by emphasizing on quality. Along with more than 100,000 employees, Volvo has been able to extend its production facilities in 19 countries and operation in more than 180 countries [37]. The main market of Volvo is in Europe, Asia and North America [37].

Main focus of Volvo Group is to create shareholders value through high qualitative products and services [38]. Volvo tries to reflect its corporate values i.e. Quality, Safety and Environment in the production system. With the vision to be valued as the world's leading supplier of commercial transport solution, Volvo has integrated safety and environmental care as a basic principle in all design work. To increase the quality of its products and services, Volvo has applied standards of ISO 9000 [39]. The "Volvo" brand name is one of the best known and respected brand names in the transportation industry which has been build up over decade with its renowned products and services [40].

\subsection{Volvo Mission \& Leadership}

Every organization has its own mission statement in which the purpose of the company is described. To attract the customers organization use mission statement as marketing strategy. Due to this reason it is important for each and every organization to know the fundamental differentiating strategy. After that organization will be able to clearly define its mission statement without any difficulty. Volvo defined its mission statement as: 
"By creating value for our customers, we create value for our shareholders. We use our expertise to create transport-related products and services of superior quality, safety and environmental care for demanding customers in selected segments. We work with energy, passion and respect for the individual' [41].

The above mission statement of Volvo is divided in two parts. Firstly it indicate that organization is considering some basic elements such as creating shareholders values, high quality of products, safety and environmental care. Secondly Volvo focuses quality of work and to create a particular working environment where employees of the organization work with energy, enthusiasm, and they respect each other working skill.

The leadership of Volvo is based on values. A clear definition of some key leadership values of the Volvo is considers a positive point of the organization. According to the objective of the Volvo, organization is giving more importance to the leadership. The demand of the successful leadership is to understand the capabilities and values in a safe and sound manner. It can be useful to judge the qualities of the potential new leaders also to develop and enhance the performance. For the improvement the customers' needs and expectation and to make high quality of product to satisfy customers, Volvo leadership is constantly operational [42].

\subsection{Corporate Culture of Volvo}

Volvo Group has unique corporate culture as compare to its competitors. Volvo has built it corporate culture and expertise since long time and to attain the Vision of the company, Volvo continuously strengthening its expertise and corporate culture. Quality, safety and environmental care are the key elements of the corporate culture of the Volvo Group. The main goal of the organization is maintain a top position in these fields [41].

As a result of the Volvo Group culture and values, employees of the company are committed to work enthusiastically to attain quality excellence and also to focus on customers, considering it as personal responsibility [43].

Volvo is identifying and visualizing the area of improvements in order to achieve the desired level of customer's satisfaction, in this way improvement plans can constantly put into practice. All the employees and as well as suppliers, dealers and business partners are encourage to work for the quality excellence. Volvo also tried to enable its employees to be responsible for customer's satisfaction and also take part in the quality improvement process [43].

In Volvo the supervision of work is done in efficient and effective manner. Ideas from customers and other are firstly check with reality. Then development procedure is constantly assessed and checked to confirm effective and efficient task. Besides, this comparison and assessment are done according to the premium industry practices. Volvo is having a proactive strategy for the development of the product [43]. 


\subsection{Manufacturing Quality-The Volvo Way}

Volvo uses six sigma and Lean to improve the quality of process by finding errors in the production system and try to minimize the wastage time. Six sigma included quality management methods and statistical methods. As shown in Figure 2, Volvo Production System consists of five key principals.

- Process stability

- Teamwork

- Built-in quality

- Just-in-time

- Continuous improvement [43]

It shows that Volvo is providing more importance to the quality as it uses the important principles for the quality of the product and services.

Sunwind is one of the suppliers of Volvo, which provide floor panel to Volvo. The supply of the floor panel was not so much effective between Volvo plant and Sunwind. To get cost benefit both companies decided to introduce Just in Time approach. Sunwind role has changed from supplier to as a partner with more responsibility for the development and manufacturing of their products to meet the requirements of Volvo. As a result of JIT approach supply floor panel has become more effective and efficient to manufacture vehicle in the Volvo plant [44].

Every organization wants to provide highest quality of product \& service to their customer which is important from the perspective of quality management. In Volvo, quality management is decentralized and certified according to ISO 9000. All the departments such as product development, product conception, customer support and sales and distributions are involved in quality management. All the departments of Volvo are conscious to maintain quality in all steps of the product life cycle. One of the good things in the total quality management of Volvo is the participation of each and every employee through conversations. Similarly, Volvo emphasizes that there should be enough knowledge about the customers in order to fulfill their requirements [39].

Volvo has a specialized quality board for the quality improvement of product

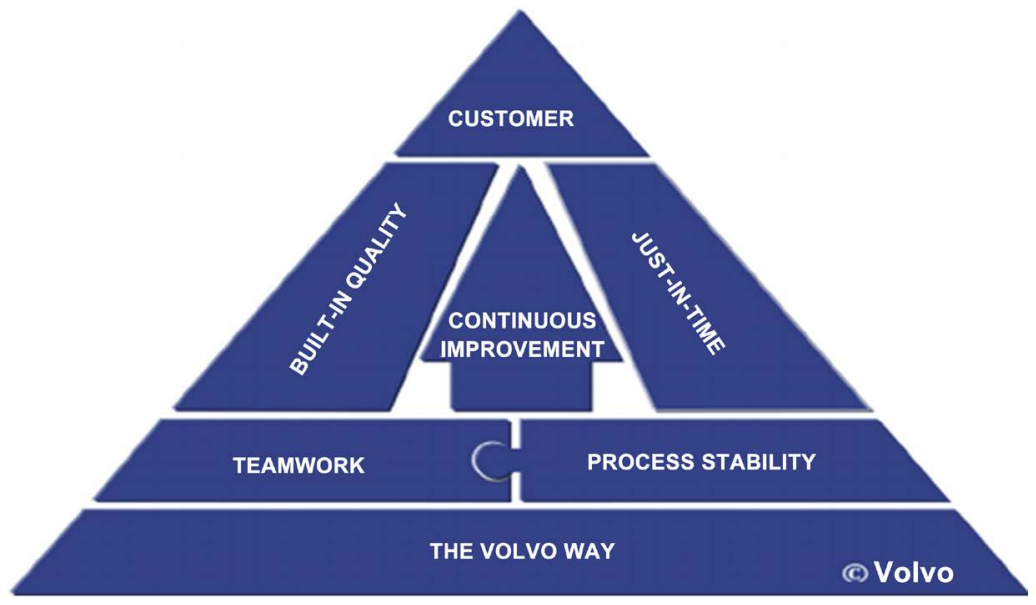

Figure 2. Manufacturing Quality The Volvo Way; Source: The Volvo Way [43]. 
and services, which is known as "The Quality Council". The Quality council is responsible body to overview the quality of the product and services in the company. The council also gives further advices for the quality improvement. Quality Council includes quality managers from each business unit and they represent their own department [39].

\subsection{Competitiveness}

In order to achieve competitive advantage Volvo Group is committed to improve their work methods constantly, enhance employee skills and utilize all resources in a proper way [45]. Apart from this, Volvo has also created a stimulating work environment that helps to improve competitiveness and attractiveness [45].

According to Volvo (2010), Volvo believes that individuals from different national and cultures provide valuable and important information, knowledge and experience. Thus they try to understand about the challenges that their global customers face because for Volvo diversity is an important asset that reinforce competitiveness [45].

Furthermore, to accomplish their long-term objectives, Volvo Group always thinks about what kind of skills they need. Therefore, every year the overall goals are split down into an individual business plan for every employee [45]. By doing so each employee is able to contribute his or her knowledge for the overall development of the company. This reflects the company culture of Volvo, which is one of the competitive assets to gain competitive advantage [45]. Energy, passion and respect for the individual are the guiding principles of Volvo's culture that enhance competitiveness. These guiding principles are the key aspects to provide customer satisfaction through top quality product and services [45].

\subsection{Quality Awards}

Volvo has got various quality awards in its sub business, such as Volvo Car Gent has got Japanese and European quality award [46]. It is an indication of that how Volvo is progressing in term of quality product and service by improving its production and manufacturing plants.

Volvo Cars Gent won two quality awards in 1999. First one is European Quality Award in the category of Operational Units and the international board of judges. TQM specialist praised Volvo Cars Gent for its distribution of Policy and Strategy; "the internal communication and the culture of Total Quality". Second one is the Japanese TPM (Total Productive Maintenance) Award for world class achievement. TPM is base on production philosophy which was invented in the field of maintenance [46].

\subsection{Volvo Problems Regarding Quality}

Volvo had faced a very harsh problem with quality in early 1950 . The problem was the door panels of their station wagon model Volvo Duett. The problem was solved by two guitar craftsmen and they had friendship with one of the worker 
of the Volvo. These two guitar craftsmen solve the problems by using different milling techniques and some other improvements process. By doing so, they are able to maintain production standard to achieve the desired level of quality [44].

In the recent past Volvo Car has also found quality problem. The problem was technical in nature and related to the increased level of oil in the diesel engine. According to the Per-Åke Fröberg spokesman of Volvo Car "The problem is that engine oil may enter the combustion chamber and act as additional fuel. This leads to maintained or increased engine speed," Because of this problem vehicle can abruptly accelerate [47].

The problem was found after some accidents in the 2009 by many customers. This problem exists in eight car model of Volvo which have diesel engine. The Volvo car informed their customers so that they can overcome this problem on temporary basis by checking oil level of their vehicle. It is also suggested that if customers see high level of oil then they should contact Volvo dealer for consultation [47].

The spokesman of Volvo car said that they have send letter to around 150,000 customers in around 30 markets in whole Europe. The purpose of this information is to inform regarding higher level of oil in diesel engines with particle filters [47]. In one of the interviews Fröberg, spokesman of Volvo car, said that customers have the possibility to overcome the problem by checking the oil level [47].

\section{Analysis}

\subsection{Total Quality Management}

Bergman and Klefsjö (2010) describe Total Quality Management (TQM) as a continuous attempt toward fulfilling and exceeding customer needs and expectation by continuously improving the working environment. As per the above empiricism, we found that Volvo has always focused in quality products. With the aim of providing excellent and regular qualitative products Volvo is maintaining total quality management in a great extent, so that customer needs are exceeded. Along with high Quality products Safety is another priority of Volvo. Their determination on quality and safety is also reflected from the Volvo mission statement. Rad (2006) has described TQM as a process of continuous improvement. We found that Volvo is implementing corporate culture of continuous improvements with the aim of providing total customer satisfaction.

Volvo leadership is based on values which mainly focus on customer satisfaction by enhancing their capabilities toward high quality of products. This kind of team work directed toward continuous improvement and customer priority are the major principles of TQM as explained by Dean and Bowen (1994). Hoogevorst et al. (2005) has suggested employees' behavior plays key role for the success of total quality management. Volvo has also been empowering its employees by giving more importance to the leadership. To empower its employees further Volvo focus on quality of work. This strategy of Volvo helped employees to work with energy, enthusiasm and respect to each other. This kind of environment is 
major factor for Volvo to maintain Total quality management in their production.

\subsection{Unique Corporate Culture}

Unique corporate culture of Volvo is another major reason for maintaining Total Quality Management within the organization. Adam (1992) defines; organization should focus on the product, process and service quality improvements and should make key strategic policy to attain world class performance to ensure the competitive advantage. With the objective of achieving vision of the organization, Volvo has been building corporate culture and expertise to attain the organizational vision. Volvo vision is directed toward continuous improvement by reflecting quality, safety and environmental care on its production process and final output.

Volvo continuously motivates its suppliers, dealers and business partners towards achieving the target of quality excellence. This has been the major competitive factor for Volvo. As Mehra and Agrawal (2003) expressed, revised quality based sustainable competitive strategy is implemented by Volvo not only to fulfill the customers demand, but also to address environmental concerns. According to Beal and Lockamy III (1999), if organization does not shows environmental concern in its production phase, then its long term sustainability target becomes difficult to achieve. Therefore, Volvo has aligned its competitive strategies along with the environmental requirements as stated by Venkatraman and Prescott (1990) to make its business sustainable.

Deming (1982) has explained the reason behind maintaining total quality management is to ensure sustainable competitive advantage. Joiner (2007) also views continuous improvement by motivating employees for quality and output not only exceed customers' expectations but also help organization to achieve competitive advantage. We have found the strategy of motivating employees and aiming high quality, applied by Volvo through identifying areas of improvements to achieve desired level of customers' satisfaction. This reflects high competitive advantage to Volvo over its competitor.

Volvo proactive strategy for development of product is also a major factor for its competitive advantage. Ideas from customers and others related to product development are first checked with the reality and according to premium industry practices. Then, Volvo implements new concept, if new concept address quality along with the environmental concerns. This process not only helps to develop the customer oriented qualitative product but also increase the level of competence for organization. Helms (1996) explain this process as a factor to reduce scrap materials and defective products. This type of customer driven strategy and employee involvement programs helped Volvo to increase their quality production level, which helped them to gain competitive advantage among its competitors.

\subsection{Six Sigma Techniques}

For continuous development and for developing organizational internal processes, 
Volvo group concentrates on the customer driven six sigma techniques. As per Helms (1996), organization should focus for continuous improvement of the process, which is more critical to the customer. Kwak and Anbari (2006) have considered Six Sigma as a business strategy, which mainly focus on customer requirements. Volvo therefore is more dedicated toward providing high qualitative products to its customers. Six sigma techniques have helped Volvo to enhance its quality production capabilities by improving quality efficiency as identified by Bal et al. (2010).

Along with this, Learn Tool-kit implemented by Volvo has been effective to eliminate wasted time and materials toward creating value to the customers by increasing quality and cost efficiency. This procedure has helped to enhance the customer satisfaction and to increase sales and financial saving as it reduces wastage in a great extent. Also, to ensure that quality programs are implemented in the operation, Volvo uses cross-functional teamwork including experts from the various field of organization. These procedures have improved its value chain like product development, purchasing, manufacturing and sales and services. Shenawy (2007) defines this kind of management commitment, team culture, training and process efficiency as a major component of TQM for ensuring high competitive advantage.

\subsection{Quality Council}

Volvo established a quality board for the improvement of quality of products and services. This council mainly gives suggestions with the objective to improve quality in every production process [39]. Powell (1995) has explained that open culture, employee empowerment and executive commitment are the vital factors to create competitive advantage. This council is directed toward providing high customer satisfactions through qualitative products. Edvardsson et al. (1999) also explains, organization should provide products and services as per the demand of customer which changes with the time [48]. Volvo, realizing this strategy thus continuously listen the viewpoint of the customers so that they can response toward the need of people by implementing the ideas of improvements suggested by the customers. This Quality council is helping Volvo to increase the level of quality from the operational phase to the final production phase.

\subsection{Quality Function Deployment}

Volvo has been applying Quality Function Deployment (QFD) approach in every level of operation i.e. product planning, product design and productive design. This approach has helped to measure and identify the critical areas of services, which directly or indirectly are decreasing customer benefits. This situation affects the customer overall satisfaction. It is one of the effective quality tools which have helped Volvo to understand the customer related problems, so that they can improve the level of quality in the operational phase to satisfy customers.

As Bergman \& Klefsjö (2010) explains, QFD has been helpful for Volvo for the purpose of market analysis and competitors' analysis. By implementing QFD, 
Volvo is able to identify the competitors' key strategies. With the help of this strategy, Volvo can further work on improving its quality products by considering major objective shared by QFD i.e. customer overall satisfaction.

\subsection{ISO Standards}

Volvo group is certified according to the ISO 9000 which ensures the quality of its product and services. All the departments of Volvo such as product development, product conception, customer support, and sales \& distribution are responsible toward quality management by implementing quality in all steps of the product life cycle. As identified by Edvardsson et al. (1999) participation of employee and customers helped Volvo to maintain its quality standards in every aspects of organizational production process. Motivational factor as identified by Singles et al. (2001) is a key reason for Volvo to maintain quality through its employee participation.

Quality culture of Volvo involves active participation of customers and employees so that, internal and external activities are strengthen not only to fulfill customers need but also to fulfill social responsibility. With the objective that strong customer care is provided during the entire ownership period, Volvo has quality improvement programs, which covers whole product series from manufacture to sales and after sales service.

The corporate values of Volvo (quality, safety and environmental care) reflect how it develops product; perform in the public and the approaches it used to contact its customers and employees. By identifying the customer quality requirement (ISO, 2010b) Volvo has been able to enhance its product and services continuously. Despite this, Volvo faced some problems in the quality of its products in 2009. But, a unique culture of Volvo strengthens its social responsibility by reaching to every customer. In response to this problem Volvo send letter to around 150,000 customers informing that they are examining high level of oil in diesel engines with particle filters [47]. This kind of Value focused approach ensures Volvo popularity and sustainable growth.

Finally, various quality awards received by Volvo also proves its determination toward providing high quality of products and services to its customers. The European Quality Award and Japanese TPM award definitely help to attract investors and customer to the products of Volvo. This creates strong competitive advantage for Volvo in response to its competitors.

\subsection{Competitiveness}

Improving their working method continuously so as to satisfy the customer needs is a major competitive strategy implemented by Volvo. Further Volvo creates stimulating working environment. This strategy helped Volvo to increase their competitiveness. Likewise, employees from diverse cultural background have helped Volvo to understand the needs of global customers. By overcoming the challenges of their global customer, diversity of Volvo employee has raised its competitiveness to the highest level as compared to its competitors. To increase 
the competitiveness, Six Sigma strategies have been implemented as a business culture in a Volvo as described by Ball et al. (2010). Energy, passion and respect are followed as guiding principles by every employee, which is acting as a key aspect to enhance customer satisfaction.

\section{Discussion}

"The Volvo Way" has created a foundation for the development of Volvo Group as a world's leading provider of commercial transport solution [49]. This approach supports for the learning environment within the organization. This approach reflects that every individual has the capability and determination to improve the operation level, because of which Volvo respects all the ideas from its customers and employees and treats them as an important.

Volvo has implemented effective quality management techniques. Laszlo (1997) explains this process helps to reduce the total cost of quality. Laszlo further explains, balance between four elements i.e. prevention, appraisal, internal failures and external failures helps to reduce the cost of quality. Through the formation of "Quality Council", Volvo is ensuring the same balance between the four elements of failure as described by Laszlo (1997). Quality Council of Volvo is ensuring to avoid failure costs by emphasizing on customer satisfaction and waste reduction. This process has helped Volvo to enhance its competence level and increase its brand image.

While defining cornerstones of TQM Bergman and Klefsjö (2010) explained organization should have focus on process, Improve continuously, Focus on Customers, Base decisions on fact, Let everybody be committed and committed leadership. In case of Volvo, we have found all these cornerstones of TQM implemented, which reflects its determination toward maintaining Quality and providing customer satisfaction. Further implementation of quality management system has helped Volvo to improve the quality of the environmental programs. Internal monitoring and the controls plays important role on this program. Jabnoun (2002) describes, control process in total quality management helps to empower employee and improve quality. Like Jabnoun (2002) explained, this control process has helped for Volvo's top management to provide necessary input for structure, skills, system and shared values.

All the business area of Volvo group focus for the environmental management systems, because of which, Volvo production plant was awarded ISO 14001 certification [50]. This process of adopting environmental management system covers the whole value chain including product development, purchasing, sales and service [50]. Since Volvo has provided its commitment toward environmental care, its reputation has increased as a world leader in safety vehicle. Through these sustainable commitments Volvo is gaining high competitive advantage.

Volvo also carryout environmental risk assessments before implementing any decisions specifically related to acquisition. As per Reed et al. (1996) strong customer care and superior quality of products are required to gain competitive 
advantage. Volvo has maintaining both strategies through the quality improvement programs on whole product series which starts from manufacturing to sales and after sales service [50]. This quality process reflects its strong competitive advantage and success factor among its competitors.

\section{Conclusions}

Organizations are using Quality as a tool to get a competitive edge over the competitor. Organizations also aim to provide quality product and services for customer's satisfaction. Higher quality can be achieved by satisfying customers, fulfilling their needs and exceeding their expectations by providing product/services as per their requirements. In the case of Volvo, we found its highly sustainable business with a constant growth. High quality products/services and very strong quality management programs are the main reason behind Volvo's competitive strength. Volvo has given priority for the participation of every employee of the organization for conversation to discuss on product improvements and quality procedures. It is clearly mentioned in the mission statement of Volvo that they are using their expertise for superior quality of product/services for the customer. Also corporate culture and key leadership values of Volvo have made them unique as compare to its competitors. This helped them to achieve high quality and thus gain competitive advantage by fully satisfying customers.

Volvo is also using various quality tools such as Six Sigma to reduce failure and defects in production process. Likewise, learn Tool-kit to eliminate wasted materials and just in time approach to avoid over-inventories. These tools help to create value for the customers by increasing quality, which provides competitive benefits to the Volvo. We have found from our study that Volvo is committed toward high quality of product and customers satisfaction in their activities. Volvo encourages customers, shareholders and stakeholder to participate in the quality improvement process. We also found that Volvo continuously motivate its employees to increase their loyalty toward organization and to ensure high quality of product and services. As a result of "Quality Council" and various other continuous quality improvement approaches, Volvo has maintained its top position in term of quality and customer satisfaction.

ISO 9000 and ISO 14001 certificates have ensured Volvo quality management system as of highest level. These ISO standards helped Volvo to improve its quality programs on whole product series starting from manufacturing to sales and after sales service. This has highly increased its competency level. Core Values of safety and quality are resembled through the Volvo brand image. Its reputation has also increased because of its commitment toward environmental care. Quality Function Deployment helped Volvo not only to analyze market but also to analyze competitors' strategies. Thus, providing overall satisfaction to the customer has been the main objective of Volvo behind maintaining quality on its product and services. These pure commitments on quality to fulfill customer satisfaction has helped Volvo to gain competitive advantage and ensured its sustainable business in this highly competitive global world. 
However, there is scope for further study in this issue. This paper can be a good lead to study further more to understand the total quality management issue and how to achieve competitive advantage. Since the business world is continuously changing, new techniques and technologies are being introduced regularly which has not been mentioned in this paper. Further investigation on this issue can be developed in future.

\section{References}

[1] Deming, W. (1982) Quality, Productivity, and Competitive Position, Center for Advanced Engineering Studies. Massachusetts Institute of Technology, Cambridge.

[2] Bergman and Klefsjö (2010) Quality-From Customer Needs to Customer Satisfaction. 2nd Edition, Studentlitteratur, Lund.

[3] Corbett, L.M., Adam, E.E., Harisons, N.J., Lee, T.S., Rho, B.H. and Samson, D. (1998) A Study of Quality Management Practices and Performance in Asia and the South Pacific. International Journal of Production Research, 36, 2597-2607. https://doi.org/10.1080/002075498192724

[4] Feigenbaum, A.V. (1961) Total Quality Control. McGraw-Hill, New York.

[5] Crosby, P.B. (1979) Quality Is Free. McGraw-Hill, New York.

[6] Garvin, D. (1984) What Does Product Quality Really Mean? Sloan Management Review, 1, 25-41.

[7] Prajogo, D.I. and McDermott, C.M. (2005) The Relationship between Total Quality Management Practices and Organizational Culture. International Journal of Operations \& Production Management, 25, 1101-1122. https://doi.org/10.1108/01443570510626916

[8] Rad, A.M.M. (2006) The Impact of Organizational Culture on the Successful Implementation of Total Quality Management. The TQM Magazine, 18, 606-625. https://doi.org/10.1108/09544780610707101

[9] Ho, S.K. and Fung, C.K. (1994) Developing a TQM Excellence Model. The TQM Magazine, 6, 24-30. https://doi.org/10.1108/09544789410073612

[10] Dean, J.W. and Bowen, D.E. (1994) Management Theory and Total Quality: Improving Research and Practice through Theory Development. Academy of Management Review, 19, 392-418.

[11] Hoogervorst, J.A.P, Koopman, P.L. and Flier, H. (2005) Total Quality Management: The Need for an Employee-Centred, Coherent Approach. The TQM Magazine, 17, 92-106. https://doi.org/10.1108/09544780510573084

[12] Beal, M. and Lockamy III, A. (1999) Quality Differentiation for Competitive Advantage: A Contingency Approach. European Journal of Innovation Management, 2, 71-81. https://doi.org/10.1108/14601069910269781

[13] Mehra, S. and Agrawal, S.P. (2003) Total Quality as a New Global Competitive Strategy. International Journal of Quality \& Reliability Management, 20, 1009-1025. https://doi.org/10.1108/02656710310500824

[14] Hill, T. (1995) Manufacturing Strategy. Irwin Professional Publishing, New York. https://doi.org/10.1007/978-1-349-13724-4

[15] Adam, E.E. (1992) Quality Improvement as an Operations Strategy. Industrial Management \& Data Systems, 4, 3-12. https://doi.org/10.1108/02635579210012223

[16] Venkatraman, N. and Prescott, J.E. (1990) Environment Strategy Coalignment: An Empirical Test of Its Performance Implications. Strategic Management Journal, 11, 1-23. https://doi.org/10.1002/smj.4250110102 
[17] Reed, R., Lemak, D. and Montgomery, J. (1996) Beyond Process: TQM Content and Firm Performance. Academy of Management Review, 21, 173-202.

[18] Shenawy, E.E, Baker, T. and Lemak, D.J. (2006) A Meta-Analysis of the Effect of TQM on Competitive Advantage. International Journal of Quality \& Reliability Management, 24, 442-471. https://doi.org/10.1108/02656710710748349

[19] Brah, S.A., Lee, S.L. and Rao, B.M. (2002) Relationship between TQM and Performance of Singapore Companies. International Journal of Quality \& Reliability Management, 19, 356-379. https://doi.org/10.1108/02656710210421553

[20] Joiner, T.A. (2007) Total Quality Management and Performance: The Role of Organization Support and Co-Worker Support. International Journal of Quality \& Reliability Management, 24, 617-627. https://doi.org/10.1108/02656710710757808

[21] Powell, T.C. (1995) Total Quality Management as Competitive Advantage: A Review and Empirical Study. Strategic Management Journal, 16. 15-37. https://doi.org/10.1002/smj.4250160105

[22] Helms, M.M. (1996) Perspectives on Quality and Productivity for Competitive Advantage. The TQM Magazine, 8, 5-10. https://doi.org/10.1108/09544789610118403

[23] Jabnoun, N. (2002) Control Processes for Total Quality Management and Quality Assurance. Work Study, 51, 182-190.

[24] Juran (1989) Juran on Leadership for Quality. Free Press, New York.

[25] Ozeki, K. and Asaka, T. (1990) Handbook of Quality Tools. The Japanese Approach Productivity Press, Cambridge.

[26] Balthazard, P.A. and Gargeya, V.B. (1995) Reinforcing QFD with Group Support Systems: Computer Supported Collaboration for Quality in Design. International Journal of Quality \& Reliability Management, 12, 43-62. https://doi.org/10.1108/02656719510089911

[27] Laszlo, G.P. (1997) The Role of Quality Cost in TQM. The TQM Magazine, 9, 410413. https://doi.org/10.1108/09544789710367811

[28] ISO (2010) ISO 9000 Essentials. http://www.iso.org/iso/iso catalogue/management and leadership standards/quali ty management/iso 9000 essentials.htm

[29] ISO (2010) ISO 9000-Quality Management. http://www.iso.org/iso/iso catalogue/management and leadership standards/quali ty management.htm

[30] Singels, J., RueEl, G. and Water, H.V.D. (2001) ISO 9000 Series: Certification and Performance. International Journal of Quality and Reliability Management, 18, 6275. https://doi.org/10.1108/02656710110364477

[31] Johannse, C.G. (1996) ISO 9000-A Managerial Approach. Library Management, 17, 14-24. https://doi.org/10.1108/01435129610119593

[32] Watson, G.H. and Yong, C.F. (2010) Design for Six Sigma: Caveat Emptor. International Journal of Lean Six Sigma, 1, 66-84. https://doi.org/10.1108/20401461011033176

[33] Green, F.B. (2006) Six-Sigma and the Revival of TQM. Total Quality Management \& Business Excellence, 17, 1281-1286. https://doi.org/10.1080/14783360600753711

[34] Kwak, Y.H. and Anbari, F.T. (2006) Benefits, Obstacles and Future of Six Sigma Approach. Technovation, 26, 708-715. https://doi.org/10.1016/j.technovation.2004.10.003

[35] Ball, P., Tjahjono, B., Vitanov, V.I., Scorzafave, C., Nogueira, J., Calleja, J., Minguet M., Narasimha, L., Rivas, A., Srivastava, A., Srivastava, S. and Yadav, A. (2010) Six Sigma: A Literature Review. International Journal of Lean Six Sigma, 1, 216-233. https://doi.org/10.1108/20401461011075017 
[36] Volvo (2010) Volvo's Founders. http://www.volvogroup.com/group/global/en-gb/volvo\%20group/history/volvosfou nders/Pages/volvo founders.aspx?print=yes

[37] Volvo (2010) The Volvo History. http://www.volvogroup.com/group/global/en-gb/volvo\%20group/history/volvosfou nders/Pages/volvo founders.aspx?print=yes

[38] Volvo (2010) Our Values. http://www.volvogroup.com/en-en/about-us/our-values.html

[39] Volvo (2010) Quality Management. http://www.volvogroup.com/en-en/news/2009/nov/news-72136.html

[40] Volvo (2010) Our Brands. http://www.volvogroup.com/en-en/what-we-do/our-brands.html

[41] Volvo (2010) Vision \& Mission Statement. http://www3.volvo.com/investors/finrep/ar06/eng/fundamentalvalues/pops/printabl e/6 vision mission.pdf

[42] Volvo (2010) Leadership. http://www.volvogroup.com/en-en/news/2016/apr/new-leadership-roles-lead-the-w ay-to-world-class.html

[43] Volvo (2010) Manufacturing Quality the Volvo Way. http://www.volvogroup.com/SiteCollectionDocuments/VGHQ/Volvo\%20Group/V olvo\%20Group/Our\%20values/volvo way eng.pdf

[44] Karlsson, C. and Norr, C. (1994) Total Effectiveness in a Just-in-Time System. International Journal of Operations \& Production Management, 14, 46-65. https://doi.org/10.1108/01443579410058522

[45] Volvo (2010) Volvo Group 2010. http://www.volvogroup.com/SiteCollectionDocuments/VGHQ/Volvo\%20Group/V olvo\%20Group/Our\%20values/volvo way eng.pdf

[46] Automotive Intelligence (1999) Volvo Cars Gent Receives European and Japanese Quality Awards.

http://www.autointell.com/european companies/volvo cars/volvo-mfg/volvo-ghent -awards.htm

[47] The Local (2010) Volvo Mulls Recall over Engine Problem. http://www.thelocal.se/20100504/26436

[48] Edvardsson, B., Gustafsson, A. and Ekdahl, F. (1999) Customer Focused Service Development in Practice-A Case Study at Scandinavian Airlines System (SAS). International Journal of Service Industry Management, 10, 344.

[49] Volvo (2010) Company Culture-The Volvo Way. http://www.volvogroup.com/group/global/en-gb/career/life\%20at\%20volvo\%20gro up/ourculture/Pages/ourculture.aspx

[50] Volvo (2010) Sustainability Report 2009. http://www.volvogroup.com/group/global/engb/responsibility/sustreport09/Pages/s ustreport2009.aspx 
Submit or recommend next manuscript to SCIRP and we will provide best service for you:

Accepting pre-submission inquiries through Email, Facebook, LinkedIn, Twitter, etc. A wide selection of journals (inclusive of 9 subjects, more than 200 journals)

Providing 24-hour high-quality service

User-friendly online submission system

Fair and swift peer-review system

Efficient typesetting and proofreading procedure

Display of the result of downloads and visits, as well as the number of cited articles Maximum dissemination of your research work

Submit your manuscript at: http://papersubmission.scirp.org/

Or contact ajibm@scirp.org 